\title{
Prozesu estokastikoak fisikan eta ekonomian: higidura browndarretik finantza-merkatuen ereduetara
}

\author{
(Stochastic processes in Physics and Economics: \\ from the Brownian motion to financial market models)
}

Naia Ormaza Zulueta*, Josu Mirena Igartua

LABURPENA: Azken hamarkadetan, ikerkuntza-talde anitzek, fisikan garatutako metodoak erabili dituzte merkatuen portaera aztertzeko. Izan ere, merkatuetako ezaugarri estatistiko sinple batzuen unibertsaltasuna nabarmena da: eskala-menpekotasunik gabeko fenomenoak antzeman daitezke (itzulkinen probabilitate-banaketetan, adibidez), fisikako hainbat esparrutan agertzen diren gisan. Hala, fisikarientzat, ekonomia ikertzea, ongi definitutako sistema konplexu bati buruzko datu ugari aztertzea bilakatu da. Aztertze-metodologia garrantzitsuenetariko bat, adibidez, prozesu estokastikoak erabiltzean datza. Izan ere, fisikan, ezaugarri unibertsalak dituzten sistema konplexu batzuen kasuan, eredu deterministak ez dira baliagarriak. Bi esparruen arteko paralelismotik, hortaz, ikuspegi estokastikoa ekonomiaren esparruan sartzea, eta merkatu estokastiko bat ereduztatzea zilegi litzateke. Hau da, kontzeptu matematiko beraz baliatuz, posible da eredu fisiko eta ekonomiko bat independenteki sortzea.

HITZ GAKOAK: Prozesu estokastiko, higidura browndar, finantza-merkatu estokastiko, Jupyter Notebook, python.

\begin{abstract}
In recent times, numerous research groups have used methods developed in physics to analyse the market behaviour. In fact, the universality of some simple statistical characteristics in the markets is noticeable: several financial variables (such as the probability distributions of stock returns) show scale invariance. These scale-free phenomena are relevant to different areas of physics. Thus, for physicists, economic research has become the study of a wealth of data on a well-defined complex system. One of the most important analysis methodologies is based on the use of stochastic processes. In fact, in the case of some complex physical systems with universal characteristics, deterministic models are not useful. From the parallelism between both areas, therefore, it would be fair to introduce the stochastic approach in the economic field and thus, model a stochastic market. In other words, it is possible to create independently a physical model and an economic model, using the same mathematical concept.
\end{abstract}

KEYWORDS: Stochastic process, Brownian motion, stochastic financial market, Jupyter Notebook, python.

\footnotetext{
* Harremanetan jartzeko / Corresponding author: Naia Ormaza Zulueta. - naia.ormazazulueta@gmail.com

Nola aipatu / How to cite: Ormaza Zulueta, Naia; Igartua, Josu Mirena (2021). «Prozesu estokastikoak fisikan eta ekonomian: higidura browndarretik finantza-merkatuen ereduetara»; Ekaia, 39, 2021, 257-276. (https://doi.org/10.1387/ekaia.21883).

Jasoa: 2020, uztaila 1; Onartua: 2020, iraila 30.

ISSN 0214-9001 - elSSN 2444-3255 / (C) 2021 UPV/EHU
}

(c) (i) () Obra hau Creative Commons Atribución 4.0 Internacional-en

lizentziapean dago 


\section{SARRERA}

Ekonomia-sektorearekin lotuta dagoen albiste bat irakurtzean, ohikoa izaten da konpainia baten egoera-finantzarioaren grafiko batekin topo egitea. Grafiko horiek konpainiaren akzioei dagozkien prezio-aldakuntzak erakusten dituzte (denboran zehar) eta, oro har, portaera oso estokastikoa antzeman daiteke prezioaren eboluzioan. Inork ez baligu irudikatutako aldagaiei buruzko informaziorik emango, bidezkoa litzateke pentsatzea edozein prozesu estokastikoren errealizazio bat daukagula eskuartean: hautspartikula baten dimentsio bakarreko higidura, adibidez. Hausnarketa honetatik lehenbizi sortzen zaidan galdera hurrengoa da: zilegi den merkatuko prezioen portaera jariakin batean murgildutako partikula baten higidurarekin nahastea.

Uretan murgildu den polen-ale baten edota airean dagoen hauts-partikula baten higidura deskribatzeko erabiltzen den fenomenoari higidura browndar deitzen zaio fisikan eta, matematikoki, denboran jarraitua den prozesu estokastiko batekin deskribatu ohi da. Prozesu estokastikoak, ordea, ez dira baliagarriak fisikan bakarrik: egungo eredu ekonomiko artifizialak eraikitzean, sarritan, prozesu estokastikoak erabiltzen dira abiapuntutzat. Hortaz, ikus daiteke, kontzeptu matematiko beraz baliatuz, eredu fisiko eta ekonomiko bat independenteki sortzea posible litzatekeela.

Lan honen helburu nagusiak dira: batetik, sistema fisiko bat eta ekonomiko bat independenteki eraikitzea eta aztertzea, eta, bestetik, horiek ezaugarritzen dituzten funtsezko propietateak komunak izan daitezkeen zehaztea.

Horretarako, lehenik eta behin, prozesu estokastikoek araututako sistema fisiko bat planteatuko da: jariakin batean dauden partikula browndarren multzo bat, hain zuzen ere. Jarraian, partikula browndarrak osatzeko erabilitako kontzeptu batzuk berrerabiliz, eta Yamada et al.-en [2] artikuluari jarraituz, prozesu estokastikoetan oinarritutako finantzako merkatu-eredu bat eraikiko da.

\section{PROZESU ESTOKASTIKOAK FISIKAN}

Probabilitate-teorian, prozesu estokastiko edo aleatorio bat da aldagai baten (eskuarki, denboraren) arabera eboluzionatzen duten zorizko aldagaien familia definitzen duen objektu matematikoa. Gaur egun, ausaz aldatzen diren sistema eta fenomenoen eredu matematiko gisa erabili ohi dira prozesu estokastikoak, eta hainbat diziplinatan aplika daitezke. Hala ere, aplikazio-eremu tradizionala fisikoa izan da, nagusiki, eta esparru horretako prozesurik garrantzitsuenetariko bati higidura browndar deritzo [1], 
arestian aipatu bezala. Jariakin batean barreiatzen diren partikula txikien higidura aztoratua deskribatzen du azken horrek eta, guztiz estokastikoa denez, prozesu estokastiko gisa baino ezin da ereduztatu. Fenomenoaren lehenengo deskribapen fisikoa A. Einsteinek eman zuen bere Annus mirabilis delako urtean publikatutako artikuluetariko batean [3].

Partikula browndarren multzo bat eraikitzeko, horien higidura deskribatuko duen ekuazioa ezagutu behar da lehenbizi. Jariakin batean barreiatzen diren partikulak deskribatzen dituzten higidura-ekuazioei Langevin-en ekuazio deritze, eta hurrengo itxura dute:

$$
\begin{gathered}
\dot{\boldsymbol{r}}(t)=\boldsymbol{v}(t) \\
\mathrm{m} \dot{\boldsymbol{v}}(t)=-\boldsymbol{\gamma} \boldsymbol{v}(t)+\boldsymbol{\xi}(t)
\end{gathered}
$$

Partikularen $t$ aldiuneko posizioa eta abiadura $\boldsymbol{r}(t)$ eta $\boldsymbol{v}(t)$ izanik, partikularen higidura deskribatuko duten Newtonen higidura-ekuazioak dira (1a) eta (1b). Indarren baturan, marruskadura-indarra eta $\xi(t)$ ausazko indarra agertzen dira. Bigarren hori, partikula browndarrari hondoko zarataren efektua gehitzen dion aldagai estokastikoa da eta, matematikoki, batezbesteko nulua duen prozesu gaussiar zuri bezala deskribatu ohi da literaturan [1]. Zarata gaussiarra zuria dela onartuz, aintzakotzat hartzen da zarata delta-korrelatua dela:

$$
\left\langle\xi_{\alpha}(t)\right\rangle=0, \quad\left\langle\xi_{\alpha}\left(t_{1}\right) \xi_{\alpha}\left(t_{2}\right)\right\rangle=b \delta\left(t_{1}-t_{2}\right)
$$

Onartuko da, bestela esanik, sistemak ez duela memoriarik. Fluktuaziodisipazio teoriari jarriki, zarata Gaussiarraren intentsitatea $b=2 \gamma k_{B} T$ dela ondoriozta daiteke [4]; hots, tenperaturaren, marruskadura-koefizientearen eta ausazko indarraren intentsitatearen arteko erlazioa.

\subsection{Partikula browndarren simulazioa}

Baldintza egokien pean, ekuazio diferentzial arruntek ebazpen bakarra dute hasierako baldintza bakoitzerako. Ekuazio diferentzial estokastikoek, bestalde, denbora jarraituko prozesu estokastikoak diren soluzioak dituzte. Horiek ebazteko erabiltzen diren metodo konputazionalak ekuazio diferentzial arruntak ebazteko erabiltzen diren tekniketan oinarritzen dira, baina egokituta daude, dinamika estokastikoa kontuan har dezaten [5].

Bestela esateko, ausazko indarra ez da jarraitua. Aldagai estokastiko bat da bere batez bestekoaren inguruan fluktuatzen dabilena, eta ez dago inolako korrelaziorik aldiuneko eta ondorengo balioen artean. Taylorren garapen batean oinarritutako integrazio-metodo hurbilduak ez direnez aplikagarriak ausazko indar bat dugunean, aldagai estokastiko berri bat kontsideratzen da, $\Delta W_{i}, t_{\mathrm{i}}$-tik $t_{i+1}$-ra bitartean partikulari eragindako bul- 
kada metatua adierazten duena. Literaturan, Wiener-en prozesu deritzo honi:

$$
\int_{t_{i}}^{t_{i+1}} \mathrm{~d} t \xi(t) \equiv \Delta \boldsymbol{W}_{i}
$$

Definizio hori aintzat hartuz, posizioaren eta abiaduraren eguneratzeekuazioak:

$$
\begin{gathered}
\boldsymbol{R}_{i+1}=\boldsymbol{R}_{i}+\int_{t_{i}}^{t_{i+1}} \mathrm{~d} t \boldsymbol{V}(t) \simeq \boldsymbol{R}_{i}+\boldsymbol{V}_{i} \Delta t \\
\boldsymbol{V}_{i+1}=\boldsymbol{V}_{i}-\frac{\gamma}{m} \int_{t_{i}}^{t_{i+1}} \mathrm{~d} t \boldsymbol{V}(t)+\frac{1}{m} \int_{t_{i}}^{t_{i+1}} \mathrm{~d} t \boldsymbol{\xi}(t)=\left(1-\frac{\gamma}{m} \Delta t\right) \boldsymbol{V}_{i}+\frac{1}{m} \Delta \boldsymbol{W}_{i}
\end{gathered}
$$

Aldiuneko posizio eta abiadura (4) eta (5) ekuazioen bitartez eguneratuz, 50 partikulaz osatutako multzo bat simulatzean lortzen diren partikulen ibilbideak 1. irudian adierazi dira.

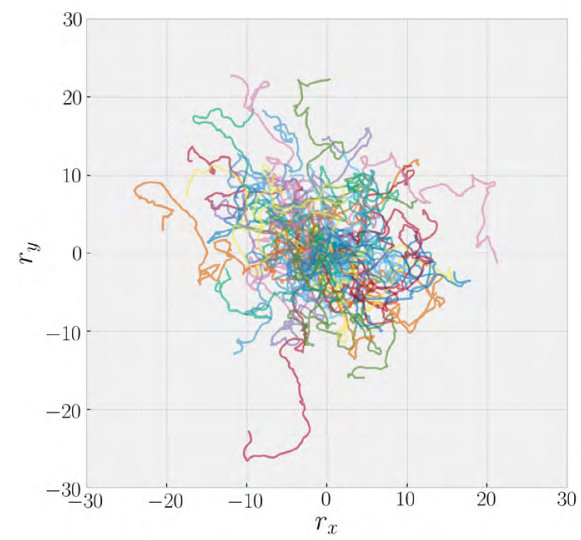

(a)

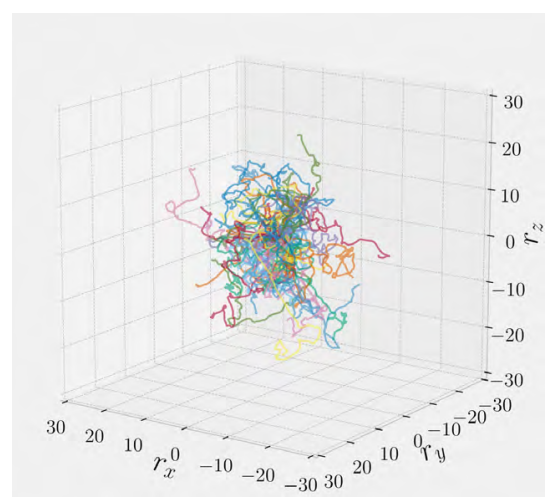

(b)

1. irudia. 50 partikula browndarren $2 \mathrm{D}-\mathrm{ko}$ (a) eta 3D-ko (b) ibilbideak, 1.000 pausutarako. Simulazio-parametroak: $m=1, \gamma=1, k_{B} T=1$, partikula guztien kasurako.

Hau da, (4) eta (5) ekuazioetako $R_{i}$ eta $V_{i}$ ikurrek $i$ aldiuneko posizio eta abiadura adierazten dituzte, $\Delta t$ integraziorako erabili den denbora-tartea da eta, azkenik, ausazko fluktuazioen efektua Wiener-en prozesuaren bitartez barneratu da. Euler-en metodo egokitu horri, literaturan, Euler-Maruyama metodoa deritzo. 
Partikula-multzoa ondo eraiki den ziurtatzeko, eskura dauden emaitza teorikoez baliatzea zilegi da. Horretarako, Langevin-en (1a) eta (1b) ekuazioen ebazpen formala behar da. Bigarrenaren ebazpena, faktore integratzailea kalkulatuz $\left(\mu(t)=e^{\gamma t / m}\right)$ lor daiteke, onartuz $t_{0}=0$ eta $v(0)=v_{0}$ direla:

$$
v(t)=v_{0} e^{-\frac{\gamma t}{m}}+\int_{0}^{t} \mathrm{~d} \tilde{t} e^{-\frac{\gamma(t-\tilde{t})}{m}} \frac{\xi(\tilde{t})}{m}
$$

Abiadura integratuz, posizioaren adierazpena zuzenean lor daiteke $\left(x(0)=x_{0}\right.$ dela aintzat hartuz):

$$
x(t)=x_{0}+\frac{m}{\gamma}\left(1-e^{-\frac{\gamma t}{m}}\right) v_{0}+\frac{1}{\gamma} \int_{0}^{t} \mathrm{~d} \tilde{t}\left(1-e^{-\frac{\gamma(t-\tilde{t})}{m}}\right) \xi(\tilde{t})
$$

Goiko (6) eta (7) ekuazioek Langevin-en ekuazioen ebazpena ematen dute, $\xi(t)$-ren errealizazio bakarrerako. Behin bi aldagaien adierazpenak lortuta, abiaduraren korrelazio-funtzioa eta batezbesteko desplazamendu koadratikoa kalkula daitezke, adibidez:

$$
\phi_{v}(t)=\frac{3 k_{B} T}{m} \cdot e^{-(\gamma / m) t \mid}
$$

eta bestalde:

$$
\left\langle\left\langle\left(\boldsymbol{r}(t)-\boldsymbol{r}_{0}\right)^{2}\right\rangle_{\xi}\right\rangle_{T}=\frac{6 k_{B} T}{\gamma}\left[t-\frac{m}{\gamma}\left(1-e^{-(\gamma / m) t}\right)\right]
$$

Aurreko kalkulu guztietarako, aintzakotzat hartu behar da $\left\langle v_{0} \xi(t)\right\rangle_{\xi}=0$ dela eta ekipartizio-teorema betetzen dela, hots, $\left\langle v_{0}^{2}\right\rangle_{T}=\frac{k_{B} T}{m} .\langle\rangle_{\xi}$ ikurrak aldagai estokastikoaren errealizazioen gaineko batezbestekoa adierazten du, goiko emaitza teorikoak kalkulatzeko halabeharrezkoa dena.

Emaitza teorikoen eta balio esperimentalen arteko alderaketa 2. irudian adierazten da. Ikus daitekeenez, simulazioaren emaitzak iragarpen teorikoaren ekuazioekin oso bat datoz, eta horrek garatutako kodea zeharo berresten du.

(8) ekuazioan, denbora-diferentziaren balio absolutuak bermatzen du korrelazioak txikiagotu egiten direla denbora-diferentzia handitu ahala. Beraz, esperimentalki lortutakoak badu zentzua, partikula browndarraren abiadurari buruzko informazioa esponentzialki txikiagotzen baita (prozesu estokastiko bat izanik, aurreikus zitekeena). 


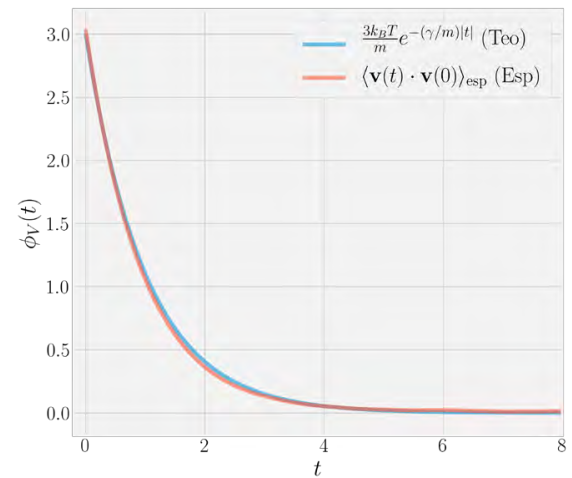

(a)

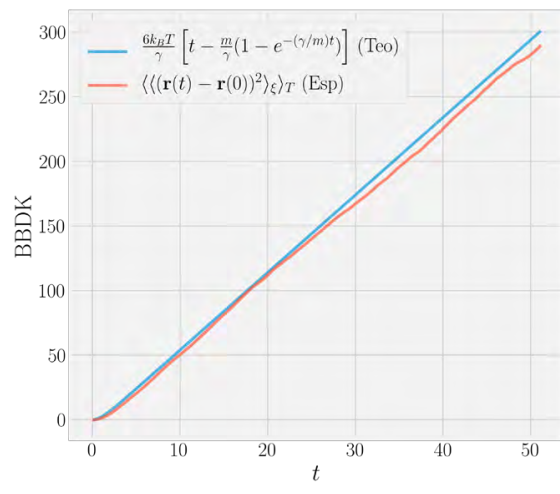

(b)

2. irudia. (a) Abiaduraren autokorrelazio-funtzioaren $\phi_{V}(t)$ irudikapen grafikoa. (b) Batezbesteko desplazamendu koadratikoaren (BBDK) irudikapen grafikoa. Urdinez, emaitza teorikoa, eta, laranjaz, emaitza esperimentaletatik lortutako datuen irudikapena.

\subsection{Jito-indarpeko partikula browndar ez-independenteak}

Aurreko atalean kasu idealena eraiki da. Hots, partikulek ez dute elkar ikusten: ez da haien arteko elkarrekintzarik existitzen, independenteak dira. Sinplifikazio hori ezartzeaz gain, bada partikulen multzoa errealitatetik urruntzen duen beste hipotesi bat. Izan ere, partikulak jariakinean simulatzerakoan, onartu da jariakina bera pausagunean dagoela, hots, ez duela inolako jito-indarrik (drift force) jasaten.

Egunerokoan, ordea, browndartzat har daitezkeen partikulen adibide batzuk honako hauek dira: hezurretan barreiatzen den kaltzioa, ibai batera erortzen diren polen-aleak, edota liburu batean pilatutako hauts-partikulak. Kaltzioaren kasuan, hezurretan xurgatua izan aurretik, odol-jario batek eramango du. Polen alea, dudarik gabe, ibaiaren korronte-fluxuaren noranzkoan higituko litzateke (uretako molekulekin talka egiteaz gain). Eta azkenik, hauts-partikulak aire-korronte baten menpe egon daitezke.

Zentzuzkoa litzateke, hortaz, jito-indar bat gehitzea (1b) ekuazioan deskribatzen den Langevin-en indarren baturari.

$$
m \dot{\boldsymbol{v}}(t)=-\gamma \boldsymbol{v}(t)+\boldsymbol{\xi}(t)+\boldsymbol{F}(t)
$$

Jito-indarra konstantea dela onartuko da: $\vec{F}(t)=F_{0} \hat{i}$ abzisen ardatzean aplikatua, adibidez. 
Posizioaren $\boldsymbol{R}(t)$ eta abiaduraren $\boldsymbol{V}(t)$ eguneratzerako Euler-Maruyama metodoa erabiliz, honako diferentzia-ekuazioak lortzen dira:

$$
\begin{gathered}
\boldsymbol{R}_{i+1} \simeq \boldsymbol{R} i+\boldsymbol{V} i \Delta t \\
\boldsymbol{V}_{i+1} \simeq\left(1-\frac{\gamma}{m} \Delta t\right) \boldsymbol{V}_{i}-\frac{\Delta W_{i}}{m}+\frac{F}{m}
\end{gathered}
$$

Jito-indarpeko partikula-multzoaren ibilbideak hurrengo irudian ikus daitezke:

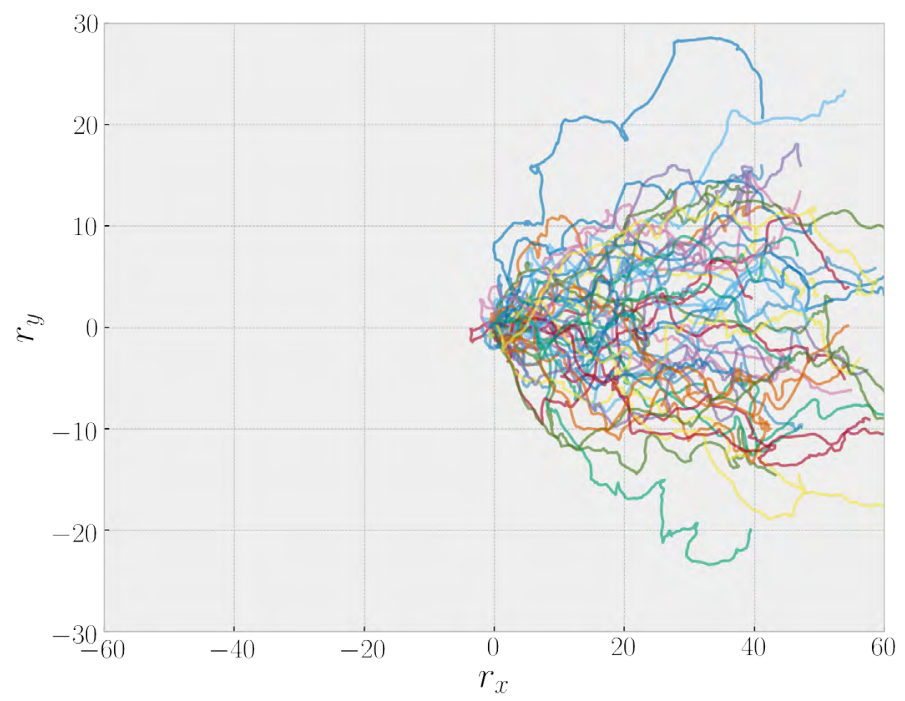

3. irudia. 50 partikula browndarren 2D-ko ibilbideak, 1.000 pausutarako. Partikula browndarrak dauden jariakinean, konstatea den jito-indar bat aplikatu da $\vec{F}=F_{0} \hat{i}$. Simulazio-parametroak: $m=1, \gamma=1$ dira, $k_{B} T=1$, partikula guztien kasurako.

Interesgarria litzateke Einstein-Smoluchowski-Sutherland [3, 6, 7] erlazioari dagokion difusio-konstantea kalkulatzea, jito-indarra presente dagoen kasu honetan. Langevin-en ekuazioan egoera egonkorra kontsideratuz $t \rightarrow \infty$ betetzen denean:

$$
\lim _{t \rightarrow \infty}\langle\dot{\vec{v}}\rangle=\lim _{t \rightarrow \infty}\left\langle-\frac{\gamma}{m} \vec{v}+\frac{\vec{\xi}}{m}+\frac{\vec{F}}{m}\right\rangle
$$

Definizioz, egoera egonkorreko abiadura-aldaketak nulua izan beharko luke. Gainera, egoera egonkorra erdiestean, abiadurak konstantea izan 
beharko du $x$ ardatzean, batezbestean, eta nulua $y$ eta $z$ ardatzetan. Bestalde, definizioz ere, badakigu ausazko indarraren batezbestekoa zero dela. Eta azkenik, jito-indarra konstantea denez, hurrengo emaitza lortzen da:

$$
0=\lim _{t \rightarrow \infty}\left\langle-\frac{\gamma}{m} \vec{v}_{x}+\frac{\vec{F}}{m}\right\rangle \rightarrow \lim _{t \rightarrow \infty}\left\langle\vec{v}_{x}(t)\right\rangle=\frac{F_{0}}{\gamma}
$$

Beraz, eta $D=k_{B} T / \gamma$ dela kontuan izanik, difusio-konstantea kalkula daiteke:

$$
D=\lim _{t \rightarrow \infty}\left\langle\vec{v}_{x}(t)\right\rangle=\frac{k_{B} T}{F_{0}}
$$

Bestela esanik, $\left\langle\vec{v}_{x}(t)\right\rangle$ adierazpena esperimentalki kalkulatzean, difusio-koefizientea berreskuratu beharko litzateke. Simulazioko datuetatik, 4. irudiko emaitza erdiesten da.

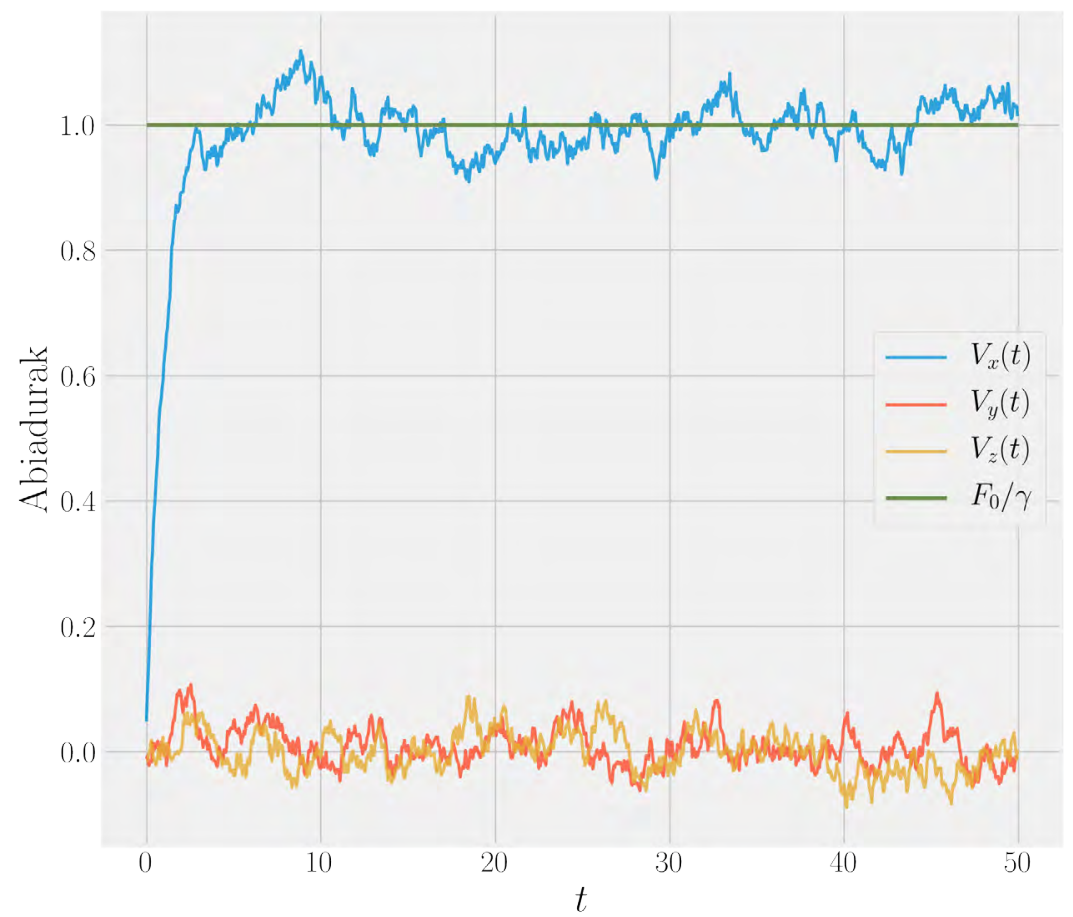

4. irudia. $V_{x}, V_{y}$ eta $V_{z}$ abiaduren osagaiak, partikula guztien batezbestekoak hartuta. Emaitza esperimentalak teorikoarekin alderatzeko, $F_{0} / \gamma$ adierazpena ere adierazita dator. 
Difusio-koefizientearen balio teoriko eta esperimentalak alderatu daitezke, bigarren hau (14) adierazpenetik kalkulatuz gero:

$$
\begin{gathered}
D_{\text {teo }}=1.0 \\
D_{\text {esp }}=0.97945
\end{gathered}
$$

Hau da, lortzen den difusio-koefizientearen balioa guztiz bat dator aurreikuspen teorikoarekin, eta horrek, simulazioko kodea berresten du.

Bestalde, partikulen arteko elkarrekintza simulatzeko, onartuko da partikula horiek Lennard-Jonesen potentzialaren mende daudela. Hipotesi hori partikula browndarren arteko elkarrekintza behatu den azterlan ugaritan aplikatu da $[8,9]$. Lennard-Jonesen potentziala (L-J potentziala, 6-12 potentziala edo 12-6 potentziala bezala ere ezagutzen dena) eredu matematiko bat da, atomo edo molekula neutro pare baten arteko elkarrekintza hurbildua deskribatzen duena. John Lennard-Jonesek 1924an proposatu zuen atomoen arteko potentzialaren forma hurrengo hau da:

$$
V_{L J}=4 \epsilon\left[\left(\frac{\sigma}{r}\right)^{12}-\left(\frac{\sigma}{r}\right)^{6}\right]
$$

Aldarapen terminoak, $r^{-12}$, oro har, Pauliren baztertze printzipioa deskribatzen du tarte laburretan. Hala ere, espinik gabeko molekula edota atomoak aztertzerakoan ere erabili ohi da. $r^{-6}$ terminoari, bestalde, irismen handiko termino erakargarria deritzo, eta maila luzeko erakarpena deskribatzen du (van der Waals indarra edo sakabanatze-indarra) [10]. Partikulamultzo baten kasurako:

$$
U=\sum_{r_{i j}<2 \sigma} \phi\left(r_{i j}\right)=\sum_{r_{i j}<2 \sigma}\left[4 \epsilon\left(\frac{\sigma}{r_{i j}}\right)^{12}-\left(\frac{\sigma}{r_{i j}}\right)^{6}\right]
$$

Goiko adierazpenean, $\vec{r}_{i j}=\vec{r}_{j}-\vec{r}_{i}$ eta $r_{i j}=\left|\vec{r}_{i j}\right|$ dira. $U$ potentziala izango da $2 \sigma$ distantzia baino gutxiagora aurkitzen diren partikula-bikoteen interakzioen batura. Lennard-Jones potentziala $r$-rekiko deribatuz, 2 partikulen arteko indar intra-partikular netoa lortzen da:

$$
\vec{F}_{i}=\frac{d U}{d \vec{r}_{i j}}=\sum_{r_{i j}<2 \sigma}\left[-48 \epsilon\left(\frac{\sigma}{r_{i j}}\right)^{12}+24 \epsilon\left(\frac{\sigma}{r_{i j}}\right)^{6}\right] \frac{\vec{r}_{i j}}{r_{i j}^{2}}
$$

Partikulen arteko elkarrekintza kontuan hartuz gero, abiadura eta posizioaren eguneratzeek askoz sistema errealistago bat sortzen dute. 


\subsection{Lortutako emaitzen laburbilduma}

Fisikaren esparruan oinarritutako lehen atal honetan, jariakin batean dauden partikula browndarren multzo bat eraiki da, Langevin-en ekuazioei jarraituz. Multzoak teorian aurkeztu beharko lituzkeen propietateak praktikan bazituela bermatu ostean, partikulen arteko elkarrekintza kontsideratu da, partikula-multzoa Lennard-Jonesen potentzialaren menpe dagoela onartuz. Partikula browndarrak aurkitzen diren jariakinari, gainera, jito-indar bat gehitu zaio, partikula-sistema errealistago bat lortzeko helburuz. Jito-indar horren pean, difusio-koefizientearen kalkulua burutu da, partikulen barreiatzea ondo gauzatzen dela ziurtatzeko.

Jariakin batean aurkitzen den partikula browndarren multzoa ereduztatzeko, prozesu estokastikoaren kontzeptuaz baliatu gara, hurrengo kapitulua garatzeko oso baliagarria izango den tresna.

\section{PROZESU ESTOKASTIKOAK EKONOMIAN}

Arestian aipatu bezala, ekonomian eta finantzetan sortzen diren arazo asko fisikan jada garatu diren kontzeptu eta metodo kuantitatiboak erabiliz azter daitezke. Egungo merkatuak, askatasun-maila askoko sistema konplexuak dira, non barne-zein kanpo-faktoreek elkarri eragiten dioten une oro, finantza-aktiboen transakzio-prezioak finkatuz. Hala ere, eragin horien funtsa ezagutzea ia ezinezkoa da, eta prezioak finkatzeko mekanismoaren izaera konplexua dela eta, eredu determinista sinpleek ezin dituzte finantza merkatuen portaerak era egoki batean erreproduzitu. Gainera, prezioak finkatzeko mekanismoaren xehetasunak merkatu batetik bestera desberdinak izan daitezkeen arren, nabarmena da prezioen gorabeheren ezaugarri estatistiko sinple batzuen unibertsaltasuna, eta horrek ikuspegi bateratu baten beharra erakusten du, askotariko merkatu-motak aztertzeko bada ere [11].

Ezaugarri unibertsalak dituzten beste sistema konplexu batzuen kasuan bezala, ikuspegi estokastikoa erabilgarria izan daiteke ekonomiaren esparruan. Ideia hori Louis Bachelier-ek aurkeztu zuen lehen aldiz, bere Théorie de la Speculation (1900) tesian. Bertan, Parisko burtsan agertzen ziren prezioen fluktuazioak, prozesu estokastikoen bidez modelizatu zitezkeela proposatu zuen [12].

Labur esanez, burtsako prezioen aldaketak eragiten dituzten zergatiak zenbatezinak dira: faktore askoren mende daude, eta, ondorioz, ez du zentzurik iragarpen matematiko baten zain egoteak. Gertakari horien ondorioz, merkatua prozesu estokastikoen bidez modelatzeko ideia sortu zen. 


\subsection{Merkatu-ereduak}

Atal honetan, eta Yamada et al.-en artikuluari [2] jarraituz, prozesu estokastikoetan oinarritutako bi merkatu-eredu eraikiko dira. Merkatu-eredu sinpleenari A Eredua deituko zaio eta hemen partaide estokastikoaren ideia aurkeztuko da. Partaide hori, merkatuan parte hartzen duen edozein negoziatzaile izan daiteke: enpresa bat, banakako merkataria, negoziatzailea, gobernua, familia edo banku zentrala. Eta estokastiko deritzo, esparru estokastiko bat erabiliz, modu baliokide batean ereduztatu daitekeelako eragile ekonomiko horietako bakoitzak ekonomian duen esku-hartzea. Hortaz, merkatu-eredua osatzen duten osagai guztiak partaide estokastikoak izango dira, eta haien arteko elkarrekintza aztertuko da.

Ondoren, ikusiko da A Eredua ez dela merkatu errealetan behatzen den funtsezko propietate enpiriko bat erreproduzitzeko gai, partikula browndarren multzoarekin gertatzen zen bezala. Partikula browndarrek, errealitatean, norabide batean barreiatzean, zentzu hobetsia izan dezakete. Eta eredua errealistago bilakatzeko helburuz, jito-indar konstante bat sartu zen. Prozedura berdinari jarraituz ekonomiaren esparru honetan, beste efektu bat gehituko zaio A Ereduari, B Eredura helduz, lehenengoaren bertsio hobetua dena eta errealitatetik hurbilago dagoena.

\subsubsection{A Eredua}

Izan bedi bi partaidez osatutako merkatu artifizial bat. Partaideek nork bere eskari- eta eskaintza-prezioak aurkezten dituzte. Eskaintza- edo eroste-prezioa da partaide batek akzio jakin batzuk erosteko eskaintzen duen prezio maximoa, aldiune horretan. Eskari- edo saltze-prezioak, bestalde, haren akzioak saltzeko onartuko duen prezio minimoa adierazten $\mathrm{du}^{1}$. Horrez gain, partaide bakoitzaren kasuan, saltze-prezioa eroste-prezioa baino altuagoa izango da (ikusi 5. irudia), merkatu batean diharduen edozein merkatariren helburua irabazi-marjina bat lortzea delako. Bi prezioen arteko diferentziari marjina deituko zaio, $L$, bi partaideentzat konstantea izango den parametroa.

\footnotetext{
${ }^{1}$ Ekonomian hobetsita daude eskaintza eta eskari terminoak, eroste edo saltze terminoen gainetik. Hala ere, lan honetan, bigarren terminologia erabiliko da, terminoen lehenengo hizkia ezberdina izanik, biak ezberdintzea errazagoa baita. Hortaz, saltze-prezioa $P_{S}$ eta eroste-prezioa $P_{E}$ agertuko dira.
} 


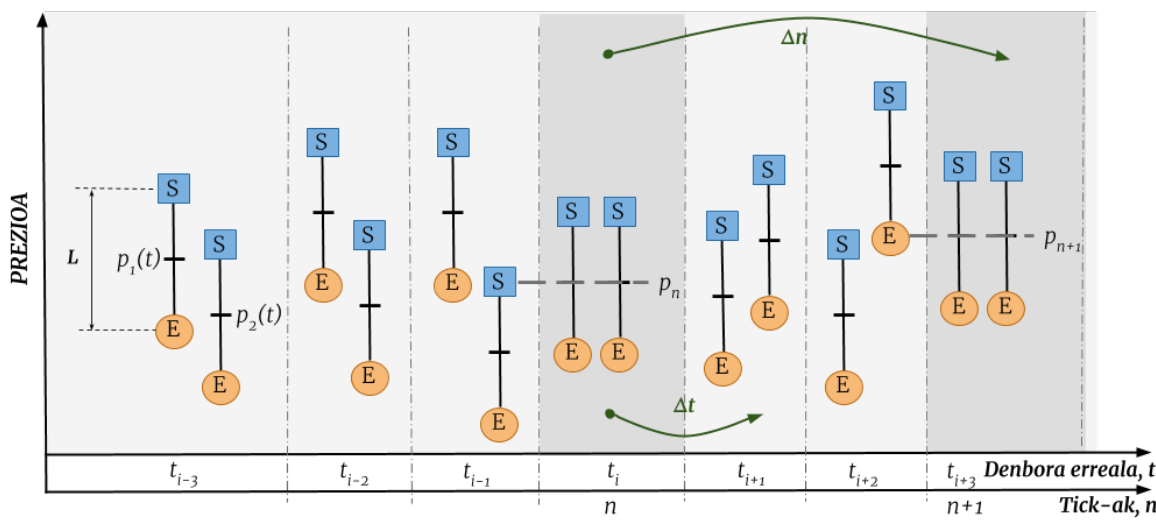

5. irudia. Merkatu ereduari dagokion denbora-eboluzio posible baten eskema. Lauki urdinek eta biribil laranjek saltze- eta eroste-prezioak adierazten dituzte, hurrenez hurren. Partaide bakoitzari dagokion batez-besteko prezioa $p_{i}(t)$-k adierazten du. Irabazi-marjina, $L$ parametroarekin adierazita dator (konstantea eta berdina bi partaideentzat). $t \in\left[t_{i-3}, t_{i-1}\right]$ denbora-tartean, ez da transakziorik burutzen: partaideen prezioek ibilbide aleatorioak jarraituko dituzte ardatz bertikalean. $p_{1}(t)$ eta $p_{2}(t)$-ren arteko distantzia $L$-ren berdina edo handiagoa denean, $t_{i-1}$ aldiunean gertatzen den bezala, transakzio bat gertatzen da. Transakzioa merkatu-prezioan gertatuko da, hau da, partaideen prezioen batezbestekoan. Puntu horretan, prozesu aleatorioa berriz hasten da.

Partaideen posizioa bereizteko, aldagai gehigarri bat sartuko da: erosteeta saltze-prezioen batez besteko prezioa, $p_{i}(t)^{2}$. Prezio horiek era guztiz estokastikoan eguneratuko dira, $t$ aldiune bakoitzean:

$p_{i}(t+\Delta t)=p_{i}(t)+c f_{i}(t), \quad i=1,2, \ldots \quad f_{i}(t)= \begin{cases}+\Delta p, & (1 / 2 \text { prob }) \\ -\Delta p, & (1 / 2 \text { prob })\end{cases}$

Adierazpen horretan $f_{i}(t)$ da $i$. partaideari dagokion ausazko zarata eta $p_{i}(t)$-ren prezioan $+c \Delta p$ gorakada edo $c \Delta p$ beherakada eragingo du. Efektu horren intentsitatea c parametroak neurtzen du. Prezioak eguneratzen diren bakoitzean, $p_{1}(t)$ eta $p_{2}(t)$ prezioen arteko distantzia neurtzen da. $L$ parametroa baino handiagoa bada, orduan, partaide baten eroste-prezioa, bestearen saltze-prezioa baino handiagoa da, eta bien artean transakzio bat gertatuko da. Bestela esanda, transakzio-baldintza honako hau da:

$$
\left|p_{1}(t)-p_{2}(t)\right| \geq L
$$

${ }^{2}$ Hemendik aurrera, batezbesteko prezioari $p_{i}(t)$ erreferentzia egiteko, prezio hitz laburtua erabiliko da soilik, hizpidea sinplifikatzeko. 
Operazioa merkatuko prezioan $P(n)$ gauzatuko da, definizioz: $P(n)=\left(p_{1}(t)+p_{2}(t)\right) / 2$.

Bi partaideen artean trukea gertatu bezain laster, nork bere ibilbide aleatorioari ekingo dio berriro ere, $P_{n}$ merkatu-preziotik (ezarri berri den transakzio-prezioa) abiatuz. Azkenik, beharrezkoa da denbora-unitate gehigarri bat definitzea, finantza esparruan askotan erabiltzen dena: tick denbora. Horrek transakzioen denbora-unitateak adierazten ditu. Hau da, transakzio bat burutzen den bakoitzean, tick denbora-unitatea batez eguneratzen da. Bestalde, denbora erreala ere badago, ibilbide aleatorioetan ematen diren pauso guztiak zenbatesten dituena.

Merkatu-ereduaren analisirako, aldagai jakin batzuen eboluzioa aztertuko da. Lehenengoa, $n$. aldiuneko $P_{n}$ merkatu prezioa izango da. Bigarrena, $n$. transakzio-tartea $I(n):(n-1)$ eta $n$. transakzioen artean igarotako denbora-tartea. Eta, azkenik, prezioen itzulkin logaritmikoa $R(t)$ :

$$
R(t) \equiv \ln P(t+\tau)-\ln P(t)
$$

Hiru aldagai horiek kontuan izanik, 6. irudian, simulaziotik lortutako merkatu prezioak, transakzio-tarteak eta itzulkin logaritmikoak irudikatu dira (artikuluan zehaztutako parametroak erabiliz), $N=5.000$ transakziotarako:
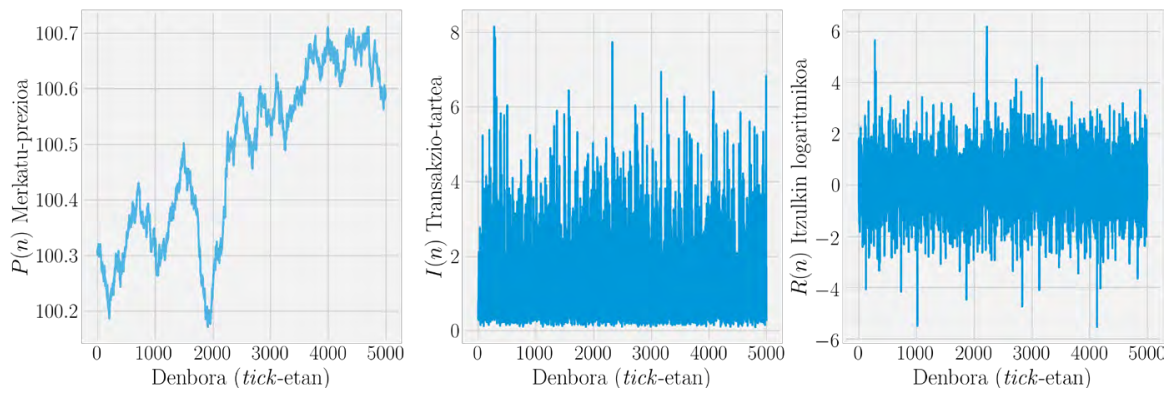

6. irudia. $\quad P(n)$ merkatu-prezioen, $I(n)$ transakzio-tarteen, eta $R(t)$ itzulkin logaritmikoen, denbora-serieen grafikoak. Denbora tick-etan neurtuta dator. Simulaziorako, $c=0.01, L=0.01, \Delta p=0.01, \Delta t=\Delta p \Delta p, p_{1}(0)=p_{2}(0)=100.3$, Yamada et al. [2] artikuluan zehaztutako parametroak erabili dira.

Itzulkin logaritmikoari erreparatuz, argi ikus daiteke prozesu estokastiko horrek izaera ez-gaussiar bat aurkezten duela: batez bestekotik 6 desbideratze tipikotara dauden balioak lortzen dira. Hau da, ohiko jokamoldetik zeharo desbideratzen diren prezio-aldaketak antzeman daitezke. Itzulkinen izaera hobeto aztertzeko, probabilitate-banaka kalkula daiteke. Datuak eskala erdi-logaritmikoan adieraziz gero, itzulkinen banaketak malda beherakor konstantekoa dela antzematen da: 


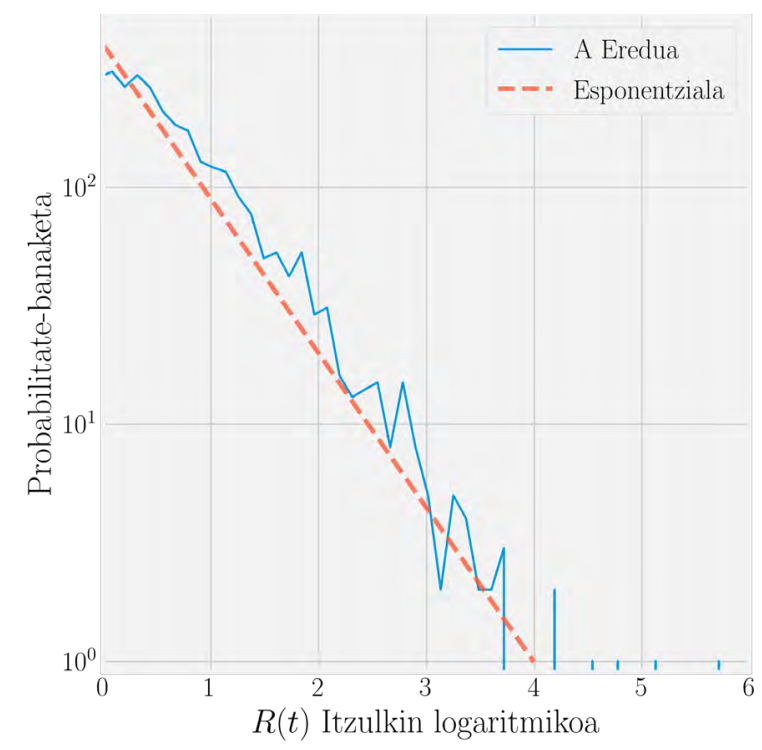

7. irudia. $R(t)$ itzulkin logaritmikoen, eta $I(n)$ transakzio-tarteen probabilitate-dentsitateak. Simulaziorako erabili diren parametroak: $c=0.01$, $L=0.01, \Delta p=0.01, \Delta t=\Delta p \Delta p$.

Argi eta garbi ondoriozta daiteke A Eredua ez dela baliagarria merkatu erreal bat ereduztatzeko. Hasteko, eta aurreikusi zen bezala, banaketa esponentziala da eta, hortaz, Poisson-en prozesu batek definitua. Merkatu erreal baten prezioaren itzulkin logaritmikoek, ordea, berreturen lege bati jarraitzen diote. Berreturen lege hori ereduztatzearen garrantzia, aurrerago azalduko da. Bien-bitartean, A Ereduak betetzen ez duen eta bete beharko lukeen propietatetzat hartuko da. Eredua hobetzeko helburuz, A. Sato eta H. Takayasu-k [13] erakutsi zutenez, «joera-jarraitzearen bidezko iragarpena» (trend-following prediction) izeneko efektua ereduztatu zuten. Bestela esateko, berreturen lege bat erreproduzitzeko helburuz, memoria efektu bat sartuko da aurreko atalean aurkeztutako A Ereduan, akzioen prezioaren itzulkinen deskribapen errealistagoa lortzea ahalbidetuko diguna.

\subsection{B Eredua}

Hemendik aurrera, batez besteko prezioa nola eguneratu erabakitzen duenean partaide batek, merkatuaren historiari buruzko ezagutza erabiliko du. Horrela, erantzun posible bat izan liteke duela gutxiko joerari jarraitzea eta prezioa gorantz bultzatzea, iragan hurbilean gora egiten bazuen, edo beherantz, beherantz bazihoan. Parte-hartzaile horiei joeren jarraitzaile de- 
ritze (trend followers). Beste aukera posiblea litzateke parte-hartzaileak iragan hurbilaren aurka joatea, garestitzen ari zen prezio bat jaitsiz, edo jaitsiz zihoan prezio bat igoz. Partaide horiei aurkariak deritze (contrarians). Joera-jarraitze efektua, aurreko atalean aurkeztutako A Ereduari gehi dakioke higidura-ekuazioetan memoria gai bat gehituz:

$$
p_{i}(t+\Delta t)=p_{i}(t)+d\langle\Delta P\rangle_{M} \Delta t+c f_{i}(t), \quad f_{i}(t)=\left\{\begin{array}{ll}
+\Delta p, & (1 / 2 \text { prob }) \\
-\Delta p, & (1 / 2 \text { prob } .)
\end{array} \quad i=1,2, \ldots(\right.
$$

non

$$
\langle\Delta P\rangle_{M}=\frac{2}{M(M+1)} \sum_{k=0}^{M-1}(M-k) \Delta P(n-k)
$$

Proportzionaltasun konstanteak, $d$ parametroak, erabakiko du merkatuko partaideak jarraitzaileak edo aurkariak diren, eta efektu horren intentsitatea zenbatekoa den bakoitzarengan. Aurreko $M$ prezio-aldaketen batez bestekoa kalkulatzen du $\langle\Delta P\rangle_{M}$ batezbesteko higikorrak. Batezbesteko hori, merkatuko prezioaren gainean kalkulatzen da eta, beraz, transakzio bat gertatzen denean baino ez da aldatuko haren balioa.

Hau da, bi transakzio-burutze artean, $d\langle\Delta P\rangle_{M}$ konstante bat izango da, partikularen ibilbideari jito-indar bat eragingo diona. Jito-indar bat gehitzen zen partikula browndarrekin ere, errealitatean behatutakoa hobeto deskriba zezaten. Merkatu-ereduen kasuan antzeko egoera agertzen da. A Ereduari termino berri bat gehituz, B Eredua, hobetua, merkatu errealen portaeratik hurbilago dagoena lortuko da.

Egokitutako azken eredu horretan, merkatu-prezioen aldaketan dago alde nabarmenena:

$$
\Delta P(n+1)=I(n) d\langle\Delta P\rangle_{M}+F(n)
$$

Eskuinaldeko lehen atalak fluxuak estalitako distantzia adierazten du; $d\langle\Delta P\rangle_{M}$ fluxuaren intentsitatea da, eta $I(n)$ transakzio-tartea. Bigarren atala, bestalde, A Ereduko prezio-aldaketan zegoen berdina da. A Ereduarekin lortutako emaitzen arabera, $I(n)$ eta $F(n)$ ausazko aldagaiak funtzio esponentzialek ezaugarritzen dituzte. Beraz, (24) ekuazioak ausazko prozesu biderkatzaile bat jarraitzen du. Kontuan hartuz ausazko prozesu biderkatzaile batetik sortutako denbora-serie batek, oro har, berreturen lege bati jarraitzen diola [14] (prozesuak egonkortasun baldintza betetzen badu), aurreikus daiteke, une horretatik aurrera, merkatu errealetan enpirikoki behatutako potentzien legea B Ereduaren bidez erreproduzitu ahal izango dela.

Aurreko adibidean, simulazioak transakzio bakar baten kasua erakusten du. $N=5.000$ transakzio burutuz gero, A eta B Ereduen alderaketa zehatzagoa egin daiteke: 

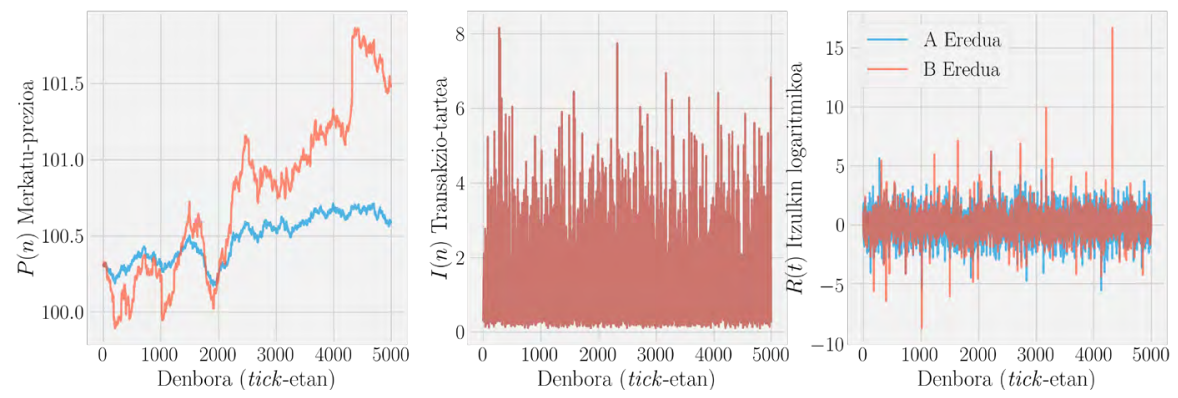

8. irudia. $\quad P(n)$ merkatu-prezioen, $I(n)$ transakzio-tarteen eta $R(t)$ itzulkin logaritmikoen denbora-serieen irudikapenak (tick-etan), A Ereduari (urdina) eta B Ereduari (laranja) dagozkionak. Simulaziorako, $c=0.01, L=0.01, \Delta p=0.01$, $\Delta t=\Delta p \Delta p, p_{1}(0)=p_{2}(0)=100.3$, Yamada et al. [2] artikuluan zehaztutako parametroak erabili dira.

Denboran zehar prezioak izan duen bilakaera ikustean, joera jarraitzen duten partaideen portaera erraz identifika daiteke (laranjaz irudikatuta): prezioak gorantz edo beherantz egitean, eboluzio horrek zenbait tick irauten du. Denbora luzean mantentzen den joerarik ez da antzematen, ordea, A Eredu guztiz estokastikoarekin.

Prezioen itzulkinei erreparatuz, zera ikus daiteke: desbideratze estandarraren unitate bat gainditzeko probabilitatea txikiago da B Ereduarekin, baina gainditzen den kasuetan, askoz ere balio handiagoak ikusten dira. Hau da, prezio-aldaketa puntual bortitzagoak gertatu dira ereduari jito-indarra gehitzean. Irudian lortutakoa bat dator teoriarekin: banaketa gaussiarrean, desbideraketa estandarra unitate batean gainditzeko probabilitatea $\% 16$ ingurukoa da; buztan lodiko (fat tail) banaketetan, berriz, desbideraketa bat gertatzeko probabilitatea txikitu egiten da (intuizioaren aurka doana). Gertatzen diren gutxiek, ordea, garrantzia handiagoa dute, N.N. Taleb-ek azaltzen duen bezala [15]. Azkenik, azpimarratu behar da, behin ere, transakzio-tartea berdin-berdina dela bi ereduentzat.

Orain, egiaztatuko da, joera-jarraipena duen B Eredu berri horrek prezioen itzulkinen banaketen iragarpen hobea egiten duen. Horretarako, eta yahoo finance-ren bidez, bi konpainia ezberdinen stock datu errealak deskargatu dira, bakoitzaren itzulkinen probabilitate-banaketak irudikatzeko. Konparaketa egiteko erabiliko diren konpainiak, Amazon merkataritza elektronikoko eta IBM teknologiako multinazional estatubatuarrak dira.

Analisirako, bi horiek aukeratu dira, beraien arteko aldea nabarmena delako. Alde batetik, IBM enpresa, 1911n sortu zen, eta 1960ko hamarkadatik aurrerako datu guztiak daude eskuragarri (yahoo finance-ren bi- 
dez deskargatu direnak). Bestalde, Amazon nahiko konpainia gaztea da; 1994. urtearen erdialdean sortu zen eta haren akzioen balioa hazten hasi zen 2012. urtetik aurrera, IBM-ren akzioen itxiera prezioak guztiz gainditu arte (9a irudia). Beraz, ez dira tankera berekoak ez bi konpainien inguruan bildutako datuen bolumena, ezta itxiera-prezioak ere.

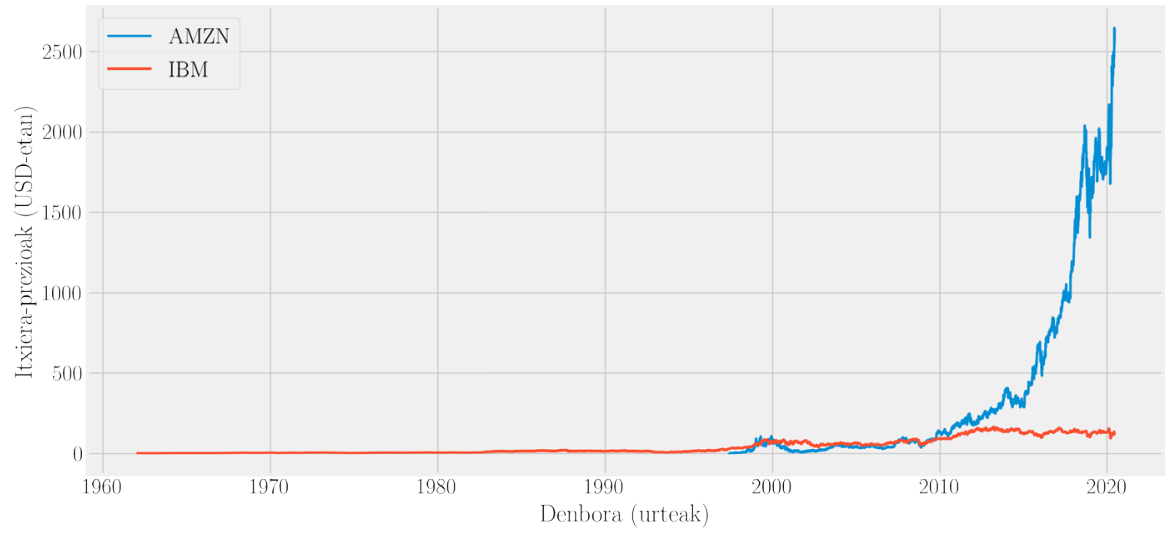

(a)

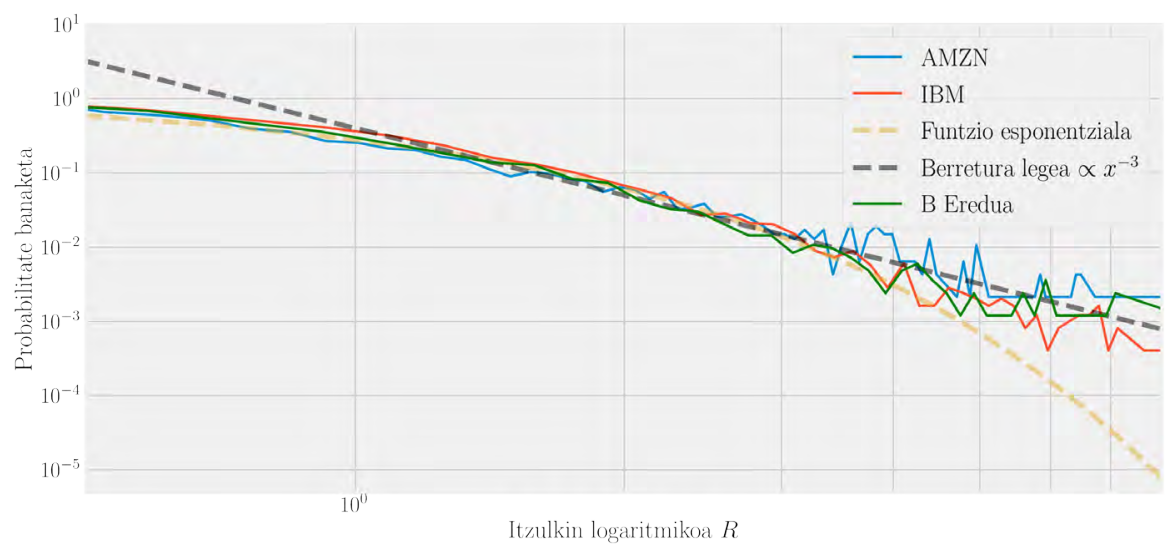

(b)

9. irudia. Amazon (urdinez) eta IBM (laranjaz) konpainien akzioen itxiera prezioak, eskuragai dauden urte guztietan zehar. Moneta USD-etan adierazita dago. (b) Prezioen itzulkinen probabilitate banaketa, log-log eskalan. Amazon eta IBM multinazionalen datu estatistikoak urdinez eta laranjaz aurkezten dira, hurrenez hurren. Berdez, B Eredutik abiatuta lortutako emaitzak. Azkenik, banaketa esponentziala (horiz) eta berreturen legeak (grisez) ere marraztu dira. Iturria: Yahoo Finance orrialdea. Eskuragai zeuden datuak IBM konpainiaren kasuan: 1962ko urtarrilaren 2tik 2020ko ekainaren 5era. Amazonen kasuan: 1997ko maiatzaren 15etik 2020ko ekainaren 5era. 
Konparazioan, bi multinazionalekin batera, B Eredutik lortutako datuak ere aztertu dira. Guztien itzulkin logaritmikoen probabilitate banaketak $9 \mathrm{~b}$ irudian alderatu daitezke. B Eredutik abiatuta lortutako simulazioaren emaitzak berdez daude; Amazonen eta IBMren datuak urdinez eta laranjaz, hurrenez hurren. Eta, ikus-gida gisa, banaketa esponentziala (horiz) eta $x^{\alpha}$ berreturen legea (grisez) ere irudikatu dira. Azken horri $\alpha=3$ berretzailea egokitu zaio datu esperimentalekin bat etor zedin. Balio hori, bat dator beste ikerketa batzuetan lortu diren emaitzekin: adibidez, P. Gopikrishnan et al.-ek Estatu Batuetako S\&P 500, Japoniako NIKKEI 225 eta Hong-Kong-eko Hang-Seng indizeak aztertu zituzten [16], eta berretzaile berera heldu ziren hiru kasuetan: $\alpha \approx-3$.

Argi eta garbi ikus daiteke, oraingoan bai, B Eredu berriak baloremerkatuko datu errealen portaera islatzen duela, berreturen legea jarraituz. Beraz, ekuazio dinamikoei memoriaren terminoa gehituz (partikula browndarren jito-indarra), merkatuko datu errealen portaera ez-tribiala erreproduzitzea lortu da. Eta, hori guztia, soilik bi partaidez osatutako eredu baten bidez.

\section{LABURBILDUMA ETA ONDORIOAK}

Lanean zehaztu diren helburu nagusiak bete dira. Alde batetik, sistema fisiko bat eta ekonomiko bat independenteki eraiki eta aztertu dira. Fisikaren esparruan, partikula browndar artifizialen multzo bat sortu dut, Langevin-en ekuazioetatik abiatuz. Bestalde, ekonomiaren esparruan, Yamada et al.-en artikuluan [2] proposatzen den eredu matematikoa hartu dut abiapuntutzat merkatu artifizial bat sortzeko. Partikula browndarren posizioa zein merkatu-partaideen prezioa eguneratzeko, ausazko zarata agertzen da higidura-ekuazioetan. Gai komun horren ondorioz, konpainia baten itxiera-prezioen grafiko bati so egiten diogunean, partikula browndar baten 1Dko higidura behatzen gabiltzala pentsa genezake. Edo alderantziz. Hau da, prezioen aldakuntza estokastikoa dela onar daiteke eta prozesu estokastikoen bitartez merkatuak ereduztatzea zilegi da, lortzen diren emaitzak onargarriak eta merkatu errealekin alderagarriak baitira.

Horrez gain, batean zein bestean, kasu errealistago bat erreproduzitzea lortu dut termino komun bat gehituz: jito-indar bat. Partikula browndarren kasuan, jito-indarra gehitzean, jariakina ez da estatikoa izango: bertan agertzen diren korronteak simulatuko ditu jito-indarrak (itsas-korronteak, airekorronteak, ibai-korronteak...). Merkatu artifizialari dagokionez, jito-indarraren bidez, merkatuaren iragan hurbila interpretatzeko eta etorkizuneko egoera aurreikusteko gai diren partaideak ereduztatu dira. Hau da, bai partikulen higidura-ekuazioan eta bai prezioen higidura-ekuazioan jito-indar bat sartuz, eredu hobea, errealistagoa lortzen dela ondorioztatu dut. 
Gai gehigarriarekin, prezio-aldaketak modu ortodoxoagoan arautu daitezkeela ikusi da, zeren eta, horrela, berreturen legea erreproduzi baitaiteke. Ezaugarri horri, literaturan, buztan lodia deitzen zaio. Buztan lodiko probabilitate-banaketa batek asimetria edo kurtosi handia erakusten du, banaketa normal edo esponentzial batekin alderatuz. Ondorioz, buztan lodiko ingurune batean, probabilitate txikia (baina oso efektu bortitza) duten gertakariak agertzea zilegi izango da. Eta kontua da gertaera bitxi horiek oso ohikoak ez badira ere, merkatuan ager daitezkeela eta, zoritxarrez, eragiten duten efektua oso boteretsua da. Ekonomiaren garapenean ustekabekoak eta garrantzia handikoak izan diren gertaera horien adibide historiko batzuk, 1929ko Wall Streeteko kolapsoa, Astelehen Beltza (1989), Dotcom burbuila, 2000ko hamarkadaren amaierako finantza-krisia edo COVID19aren ondoriozko 2020ko balio-merkatuaren kolapsoa dira. Gertaera horiek ezingo lirateke banaketa gaussiar baten bidez erreproduzitu [17].

Bi kasuetan, benetako fenomeno bat ereduztatzea da helburua. Baina, funtsean, ereduak direnez, inoiz ezin izango dituzte zehatz-mehatz eta koherentzia osoz sistema konplexuen (balore-merkatuen edo hondar ale baten ozeanoko higiduraren) ezaugarri guztiak deskribatu. Hala ere, eredu matematiko bat garatzeko halabeharrezkoak diren baldintzak bete dira [18]: egitura matematiko bat eraiki da bi esparruetan, ingurune erreal bat deskribatzen duten magnitudeen arteko erlazioei buruzko hipotesietan oinarrituz. Eta, bestalde, eredua ebaluatzea lortu da, egungo mundutik modu enpirikoan lortutako ezaugarriekin alderatuz. Ereduak guztiz ontzat har daitezke, lan honetan exijitu zaien konpromisoa bete dutelako: partikula browndarren higidura ondo ereduztatu dela frogatu dugu (emaitza teorikoak kontuan izanik), eta, finantza-merkatu artifizialaren kasuan, berreturen legea erreproduzitzea lortu da.

George E.P. Box matematikari eta estatistikoak esan zuen bezala, all mathematical models are wrong, but some mathematical models are useful [19] (eredu matematiko guztiak oker daude, baina horietako batzuk baliagarriak dira). Puntu honetara iritsita, ez gara inolaz ere balore-merkatuak aurreikusteko edo finantza-inbertsioko estrategia bat garatzeko gai. Eztabaida horiek lan honen irismenetik kanpo badaude ere, modu arrazoituan erakutsi ahal izan da fisikaren eta ekonomiaren esparruek funtsezko ezaugarriak izan ditzaketela, eta fisikan garatutako baliabideekin posible dela arazo ekonomikoez jardutea.

\section{BIBLIOGRAFIA}

[1] L. E. Reichl . 2009. A Modern Course in Statistical Physics. 4th Edition. Wiley.

[2] K. Yamada, H. Takayasu, T. Ito, eta M. Takayasu. 2009. «Solvable stochastic dealermodels for financial markets». Physical Review E, 79, 5. 
[3] A. Einstein. 1905. «Über die von der molekularkinetischen Theorie der Wärme geforderte Bewegung von in ruhenden Flüssigkeiten suspendierten Teilchen». Annalen der Physik, 322, 8, 549-560 orr.

[4] R. Zwanzig. 2001. Nonequilibrium statistical mechanics. Oxford University Press.

[5] T. Sauer. 2013. «Computational solution of stochastic differential equations». WIREs Comput. Stat. 5, 2, 362-371 orr.

[6] M. von Smoluchowski. 1906. «Zur kinetischen Theorie der Brownschen Molekularbewegung und der Suspensionen». Annalen der Physik, 326, 14, 756-780 orr.

[7] W. Sutherland. 1905. «A dynamical theory of diffusion for non-electrolytes and the molecular mass of albumin». The London, Edinburgh, and Dublin Philosophical Magazine and Journal of Science. 9, 54, 781-785 orr.

[8] J.J. Brey eta J. G. Ordóñez. 1987. «Computer studies of Brownian motion in a Lennard-Jones fluid: The Stokes law». The Journal of Chemical Physics, $76,6,3260-3263$ orr.

[9] S. Lee. 2010. «Friction between Two Brownian Particles in a Lennard-Jones Solvent: A Molecular Dynamics Simulation Study». Bulletin of the Korean Chemical Society, 31.

[10] P.W. Atkins eta J.C. de Paula. 2010. Physical chemistry for the life sciences. Oxford University Press. 290,469-472 orr.

[11] W. Paul eta B. Jorg. 2016. Stochastic processes: from physics to finance. 2. ed. Springer.

[12] L. Bachelier. 1900. «Théorie de la spéculation». Annales scientifiques de l'École Normale Supérieure, 3, 17, 21-86 orr.

[13] A.-H. Sato eta H. Takayasu. 1998. «Dynamic numerical models of stock market price: from microscopic determinism to macroscopic randomness». Physica A: Statistical Mechanics and its Applications, 250, 1, 231-252 orr.

[14] S. Morita. 2006. «Power law in random multiplicative processes with spatiotemporal correlated multipliers». EPL (Europhysics Letters), 113, 4.

[15] N.N. Taleb. 2007. The Black Swan: The Impact of the Highly Improbable. Random House Group.

[16] V. Plerou, P. Gopikrishnan, L.A. Nunes Amaral, M. Meyer eta H.E. Stanley. 1999. «Scaling of the distribution of price fluctuations of individual companies». Physical Review E, 60, 6.

[17] C.-F. Lee, A. Lee eta J. Lee. 2010. Handbook of Quantitative Finance and Risk Management.

[18] S.R. Dunbar. 2016. Mathematical Modeling in Economics and Finance: Probability, Stochastic Processes and differential Equationst. MAA Press.

[19] G.E.P. Box, 1976. «Science and statistics». Journal of the American Statistical Association, 71, 356, 791-799 orr. 